trazada sobre el muro como ideograma arquitectónico, o la línea recta implacable y deliberadamente dibujada como medio conductor, son algunas de las fórmulas utilizadas y reafirmadas conceptualmente por Juan Gómez de Mora en su búsqueda de una arquitectura de articulación clara, de trama geométrica precisa cuya clave artística siempre se asocia a la idea de disciplina formal.

El proyecto que hoy añadimos a su ya extenso catálogo viene a confirmar una vez más la coherencia estilística que le caracteriza; y lejos de cualquier beligerancia, Juan Gómez de Mora confirma en esta obra una vez más su serio y riguroso sentido de la experimentación arquitectónica pragmática. El efecto plástico de la casa de los Condes de Barajas en el dibujo de Juan Gómez de Mora subraya el valor de la sencillez, de la belleza del material sin desnaturalizar su sustancia y también la significativa prestancia de la superficie desnuda. En el tema de la arquitectura ciudadana plurifamiliar, este arquitecto supo dar un importante salto cualitativo con obras en las que se saturan en armonioso juego materiales sencillos y elementos geométricos escuetos.

CRistóbal Marín Tovar

Documento de la Nobleza. Colec. Fernán Núñez Legajo 1619/24

Dibujo a tinta gris, negra y roja. Firmado y rubricado Juan Gómez de Mora. Nota manuscrita «Conforme a esta traza sea de labrar la delantera del sitio que se da a S. Exm el conde de Barajas conforme a lo que de antes había en la acera de los mercaderes que viene a ser en el claro número 10 y número 11 contando de la rinconada de la cava anse de poner las pilastras de piedra de dos pies en quadrado y por la frente dos dedos menos de alto con bassa y capitel quinze pies poco mas o menos asta la biga de frente que el primer suelo ande quatro pies mas bajo que el de la Panaderia el terrado a de ser de plomo con antepechos de hierro todos los balcones asi mismo lo an de ser el primero a de ser entero y de vuelo 3 pies y de nueve pies de largo los demas de alli arriba y de buelo dos pies y medio y desde laplaza a los soportales se ha de salir con una grada de de medio pie de alto y las maderas asi de la biga como las de los soportales a de ser conforme al auto de la junta y de ancho los soportales con grueso de pilastras dieciseis pies y el tijaroz de madera conforme a la muestra y se advierte que antes de empezarla dicha obra se ha de presentar esta traza ante los Señores de la Junta para que se señale el sitio quer su Excelencia a de tener y se aga la medida y quenta segun la planta general de esta obra questa acordada. En Madrid a 11 de mayo de 1628. Juan Gomez de de Mora.»En el ángulo superior "En Conde de Barajas Acera de los Mercaderes. Plaza Mayor de Madrid» Rubricado por el mismo arquitecto.

\title{
UN CUADRO INEDITO DE DANIEL DE VOS EN ESPAÑA
}

La presencia de pintura flamenca en España no ha constituido nunca una novedad, salvo cuando se trata de la obra de un artista poco conocido o escasamente representado en nuestro país. Este es el caso de Daniel de Vos (1568-1605), un pintor del que apenas si conocemos algún dato aparte de su formación en el taller de su padre, Martín de Vos (1532-1603), y su ingreso en las Guildas de Flandes ${ }^{1}$.

1 El conocimiento actual de la vida y obras de Daniel de Vos es tan escaso que sólo encontramos breves referencias a él en los grandes diccionarios de arte. Así el reciente The Dictionary of Art editado por Jane Turner (MacMillan, Londres, 1996, vol. 32, p. 709) sólo incluye una breve mención dentro de la voz referida a su padre: «In his second will of 10 October 1603, de Vos bequeathed his painting equipment, drawings and the like to his sons Daniel de Vos (1568-1605) and Marten de Vos the younger (1576- 1613).» Obras anteriores como la de E. Benezit, Dictionnaire des Peintres, Sculpteurs, Dessinateurs et Graveurs (Librairie Gründ, París, 1966, vol. 8, p. 623), son igualmente escuetas: «Peintre, baptisé à Anvers le 25 mai 1568 , mort en 1605 (Ec. Flam.). Fils de Marten de V. "; o, como U. Thieme-Becker, Allgemeines lexikon der Bildenden Künstler (Seeman, Leipzig, 1976-1983, vol. XXXIV, pp. 553 y 555), apenas si lo mencionan como hijo de Martín de Vos.

En lo que se refiere a la presencia de su obra en España, tenemos que agradecer a don Matías Díaz Padrón la noticia de la existencia de varios cuadros de Daniel de Vos en nuestro país, que permanecen inéditos aún; sin que conozcamos que se haya publicado en España alguna otra obra del pintor flamenco. 
La obra de Daniel de Vos que presentamos aquí es un San Jacobo ermitaño (óleo sobre lienzo, $150 \times 192 \mathrm{~cm}$.) que pertenece a una colección particular cordobesa y se encuentra actualmente en mercado (Figs. 6 y 7). La pintura muestra la figura de un eremita vestido con un sayal de esparto, que está golpeándose el pecho con una piedra en un gesto de penitencia junto a una tumba llena de huesos humanos. El personaje se encuadra en un paraje aislado en el que se abre al fondo una perspectiva donde se trazan unos campos cultivados en torno a una ciudad de arquitectura italiana, que destaca por su buena factura en contraposición al poco cuidado de los sembrados. En el plano más cercano, el santo está acompañado por una corriente de agua, un denso follaje vegetal y varias flores y animales primorosamente pintados: dos pájaros, una tortuga y dos mariposas, mientras que a sus pies se encuentra también un rosario. El cuadro está firmado en una de las esquinas del sarcófago: $D A$ NIEL DE VOS, $F$ (fig. 8) y presenta la siguiente leyenda en su parte inferior: DEXTERA NE FLAMMA(M) RAPIAT, CREMAT IGNI SINISTRA / SIC IACOBE MANU TACTA PUELLA CALET / VICISTI IUVENIS. CANUM QUI FEMINA VICIT / IN THALAMO PECCAS, CORRIGIS IN TUMULO.

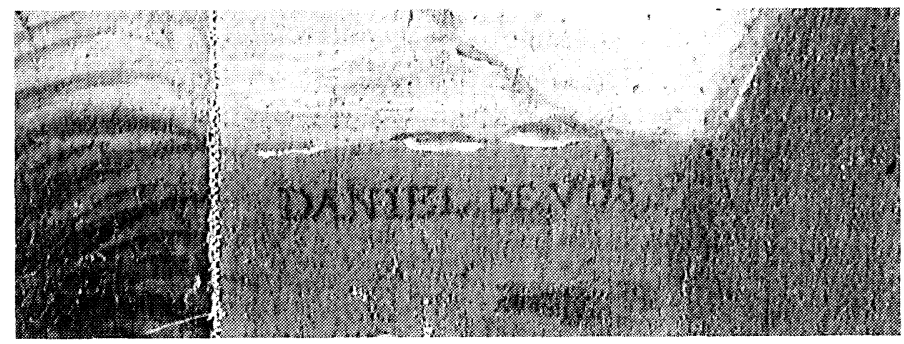

Fig. 8. Daniel de Vos, San Jacobo Ermitaño, detalle de la firma. Córdoba. Colección particular.

Podemos identificar el asunto con la representación de la historia de San Jacobo ermitaño y confesor que se describe en el De probatis sanctorum historiis de Lorenzo Surio, tal y como nos explica la inscripción anterior ${ }^{2}$. El santo aparece en su segundo retiro, cuando vivía en un ataúd junto a los restos de varios esqueletos para cumplir penitencia por sus pecados. Jacobo había llevado en el pasado una vida ejemplar de meditación y virtud por la que había vencido a las tentaciones en numerosas ocasiones, incluso cuando en su juventud tuvo que meter la mano derecha en el fuego para no ceder ante una joven que le había enviado el propio diablo, pero ya en la vejez no pudo resistirse a una prueba similar, y no sólo cayó en pecado con esa muchacha, sino que la mató después para esconder la acción. Entonces es cuando se retira al desierto por segunda vez para redimir su culpa, viviendo aislado dentro de un sarcófago y en continua mortificación, como nos muestra De Vos en el cuadro.

Por otro lado, y como suele ser habitual en la pintura flamenca de fines del siglo xvi y comienzos del xvir, la importancia del tema se reduce ante la valoración que recibe el paisaje en el que se encuadra, y la profusión de pequeños detalles naturalistas que acompañan al personaje central. De tal forma que aunque estos elementos abunden en la historia de San Jacobo, como lo hacen la ciudad que se atisba al fondo y que puede recordar al pueblo del que procedía la primera joven, o el río que está a su izquierda y al que arrojó su cadáver, sin embargo la descripción poética de los animales y plantas que rodean su retiro puede acabar por distraer la atención del espectador oscureciendo el fin moralizante.

Antonio Urquizar Herrera (Universidad de Córdoba)

\footnotetext{
2 En la edición de Colonia, 1570; fol. 721 y ss. Esta misma edición germana servirá después a Alonso de Villegas como base para el texto sobre el mismo santo que incluye en su Flos Sanctorum (Toledo, 1589, pp. 137b y ss.)
} 